\title{
SISTEMAS DE INFORMAÇÃO
}

A despeito do crescente número e variedade de aplicações de tecnologias de informação e comunicação (TIC), e da ampliação dos conteúdos, direções e tendências na disciplina de Sistemas de Informação (SI), as aplicações práticas estão quase sempre à frente de qualquer tipo de sistematização teórica. 0 principal exemplo desse descom- passo é a Internet, que surgiu e se desenvolve à revelia dos estudos de SI. Para ajudar a situar al guns dos problemas de pesquisa na área, Eduardo H. Diniz, professor da FVG-EAESP, recomenda as seguintes indicações de literatura, com foco em metodologias e temas de pesquisa em SI:
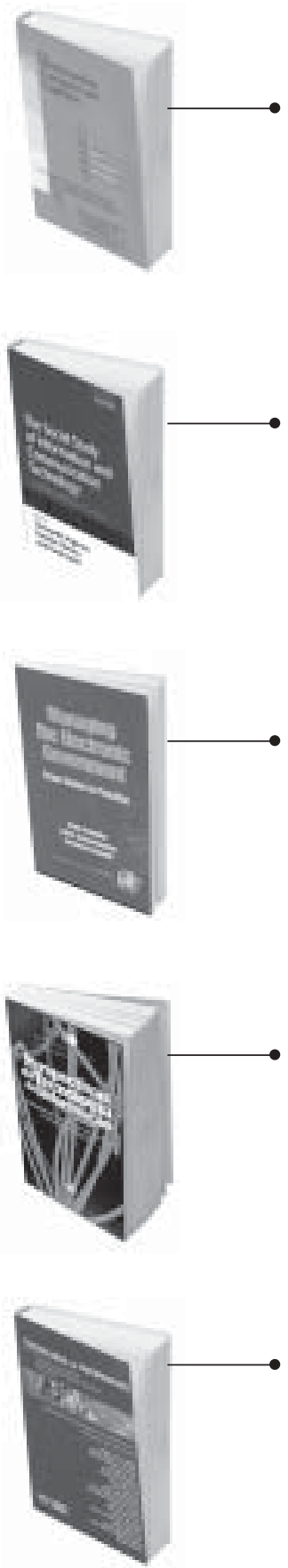

UNDERSTANDING COMPUTERS AND COGNITION: A new foundation for computer system design. Terry Winograd e Fernando Flores. Chichester, UK: John Wiley, 1986. 224 p.

A obra é um clássico do pensamento sociotécnico em SI. Escrito no período inicial do desenvolvimento da área, os autores apontam a contradição entre o "paradigma lógi co-matemático" predominante na área e o que acreditam que deveria compor a base para a construção dos "fundamentos teóricos" de SI. Afirmam que uma abordagem multifacetada e composta por visões de outras áreas acadêmicas, como a biologia, a hermenêutica e a fenomenologia, podem contribuir para desenvolvimentos teóricos em SI, no sentido de torná-la mais relevante para o mundo prático.

THE SOCIAL STUDY OF INFORMATION AND COMMUNICATION TECHNOLOGY: innovation, actors, and contexts. Chrisanthi Avgerou, Claudio Ciborra e Frank Land (Eds.). Oxford: University Press, 2004. 290 p.

Organizado por professores da London School of Economics, a obra reúne contribuições de mais de uma dezena de autores preocupados com o desenvolvimento de uma teoria social para a área. 0 livro é composto por três grandes blocos: no primeiro se apresentam os fundamentos para 0 estudo fenomenológico de SI, para a construção de uma sociologia própria das TICs; no segundo se exploram perspectivas conceituais para as orientações teóricas apresentadas no primeiro bloco; e no terceiro são apresentadas questões específicas direcionadas aos pesquisadores.

MANAGING THE ELECTRONIC GOVERNMENT: from vision to practice. Kuno Schedler, Lukas Summermatter e Bernhard Schmidt. Greenwich, Connecticut: Information Age Publishing, 2004. 158 p.

O tema "governo eletrônico" talvez seja um dos que mais evidenciam as dificuldades da área acadêmica de SI para formular conceitos suficientemente relevantes para consolidar teorias em torno da crescente informatização da sociedade. N ove entre dez livros sobre esse tema são meros relatos de casos, que não contribuem para entender mais profundamente esse fenômeno. A obra é uma tentativa de preencher essa lacuna ao buscar a construção de um modelo teórico que possa ser aplicado na prática, utilizando exemplos que dêem suporte às idéias apresentadas.

PERSPECTIVAS DA TECNOLOGIA DA INFORMAÇÃO: edição 2004. OCDE. São Paulo: Editora Senac, 2005. 494 p. Relatório do grupo de trabalho sobre economia da informação do Comitê das Políticas de Informação, Informática e Comunicações da OCDE (Organização para a C ooperação e o Desenvolvimento Econômico), o livro é rico em dados sobre a indústria das TICs no mundo, e aborda a evolução do comércio eletrônico, de novas tecnologias, bem como o governo eletrônico e as políticas tecnológicas nos países da OCDE. Referência importante para se manter atualizado com os dados globais do setor.

TECNOLOGIA DA INFORMACÃO. Alberto L. Albertin e Rosa M. de Moura (Orgs.). São Paulo: Editora Atlas, 2005. $207 p$.

A obra é constituída de 12 artigos e conta com a colaboração de duas dezenas de autores tanto da academia quanto do mercado de tecnologia da informação no Brasil. Os temas abordados variam da implementação de sistemas e alinhamento entre tecnologia e negócios a mercados de softwares e indicadores de tecnologia. Talvez o principal mérito do livro seja a sua atualidade e a identificação de al guns dos tópicos mais rel evantes que estão sendo investigados na área de SI no país. 